\title{
Reference Values of Static Back Extensor Muscle Endurance in Healthy Nigerian Adults
}

\author{
Chidozie Emmanuel Mbada ${ }^{a}$ Olusola Ayanniyi ${ }^{c}$ Rufus A. Adedoyin ${ }^{b}$ \\ a Department of Physiotherapy, Obafemi Awolowo University Teaching Hospitals Complex, and \\ ${ }^{b}$ Department of Medical Rehabilitation, Obafemi Awolowo University, Ile-Ife; ' Department of Physiotherapy, \\ College of Medicine, University of Ibadan, Ibadan, Nigeria
}

\section{Key Words}

Static endurance - Back extensor muscles - Sørensen test •

Nigerian adults

\begin{abstract}
Objective: This study aimed to establish gender and age reference values of static back extensor muscle endurance in healthy Nigerian adults. Subjects and Methods: This study involved 373 consecutive participants aged between 21 and 60 years who were grouped into four age strata. A modification of the Sørensen test of Static Muscular Endurance (BSME) was used to quantify static endurance. The mean, standard deviation, range and 25th, 50th, and 75th percentile scores were determined for four gender/age categories. Results: Endurance time differed significantly across the age groups $(F=47.286 ; p=0.000)$. Males exhibited higher mean endurance than females $(t=2.583 ; p=0.010)$. Using percentiles, 25th (poor endurance), 25th-75th (medium endurance) and $>75$ th (good endurance) percentile were $72,72-161$, and $>161-240 \mathrm{~s}$, respectively, for males; and 64, 64-142, and $>142-236 \mathrm{~s}$, respectively, for females. There was an age and gender variation in the median values. The results suggest that the significant age and anthropometric differences between the categories of participants could contribute to endurance differences. Conclusion: This study established a set of reference values for static back endurance in healthy
\end{abstract}

Nigerians. These values can be used to compare a patient's score at intake or as an outcome measure in clinical practice.

Copyright $\odot 2009$ S. Karger AG, Basel

\section{Introduction}

Muscular endurance is the ability of an isolated muscle group to perform repeated contraction over a period of time (dynamic endurance) [1] or sustain contraction over time at a certain level (static endurance) [2]. The Biering-Sørensen Test of Static Muscular Endurance (BSME) either in its original version or as a variant has been widely used in the assessment of static endurance of the back extensor muscles in health and disease [3-7]. Ropponen [8] in a recent study summarized that the BSME can be used for monitoring the effects of intervention or rehabilitation [9] and also in evaluating working capacity, investigation of back disorders, as well as being useful in preventive medicine and related to maintenance or enhancement of back muscle function [10].

There is some evidence that decreased muscular endurance could be a cause, as well as a consequence, of certain musculoskeletal disorders [10]. Low levels of static endurance in the back extensor muscles are associated with higher rates of low back pain (LBP) [11], decreased

Chidozie Emmanuel Mbada, MSC (PT), MNSP

\begin{tabular}{ll}
\hline KARGER & (c) 2009 S. Karger AG, Basel \\
Fax +41613061234 & 1011-7571/09/0185-0345 $\$ 26.00 / 0$ \\
$\begin{array}{l}\text { E-Mail karger@karger.ch } \\
\text { www.karger.com }\end{array}$ & $\begin{array}{l}\text { Accessible online at: } \\
\text { www.karger.com/mpp }\end{array}$
\end{tabular}

Obafemi Awolowo University Teaching Hospitals Complex

Ile-Ife (Nigeria)

Tel. +2348028252543

E-Mail doziembada@yahoo.com 
proprioceptive awareness [12], poor balance [13], and decreased productivity in the workplace [5], increased muscular fatiguability measured with EMG $[4,14]$ and soft tissue overloads and passive structures of the lumbar spine [15].

Lack of baseline or reference values is a limitation in the quantification of physical performance of the muscles of the back. McIntosh et al. [16] reported that when evaluating muscle performance in the extremities, an examiner can compare the normal and abnormal sides to quantify diminished function. They concluded that this type of intrinsic control is not available for evaluation of the trunk. Therefore to identify alterations of the trunk musculature from 'normal', a normative database is needed [16]. Comparing back endurance test results of patients with LBP to reference data of healthy subjects may help identify the presence of an impairment and in turn inform the plan for appropriate intervention based on the assessment of the extent of muscular dysfunction. The medical literature contains little data concerning the normal endurance capacity of the back muscles [16]. However, a few normative databases using the Sørensen test or its variants currently exist for some populations $[10,16$, 17]. To date, there is a paucity of reference values of static back extensor muscle endurance in the Nigerian population. This study aimed to establish gender and age reference values of static back extensor muscle endurance in healthy Nigerian adults using the BSME.

\section{Subjects and Methods}

The ethical approval for this study was obtained from the University of Ibadan/University College Hospital Institutional Review Committee. The participants were fully informed about the purpose of the study and their consent was obtained before measurements were taken. Consecutive samples of 376 healthy volunteers between the ages of 21 and 62 years were recruited. The participants were volunteers who included staff, students and patients' relatives recruited via research advertisements and invitations from the University of Ibadan, University College Hospital, Ibadan and the surrounding metropolis, Ibadan, Nigeria.

Participants for this study were screened via interview to ensure that they satisfied the selection criteria for the study. Exclusion criteria were a history of symptomatic LBP within 1 year to the time of the study; any obvious spinal deformity or neurological disease; participation in high-intensity regular exercise or elite sports at a competitive level or being involved in any prior systematic exercise program of the lumbar or hip extensor muscles; a history of cardiovascular diseases representing contraindications to exercise; being pregnant, and any disability limiting the ability to exercise.

\section{Measurements}

Anthropometric measurements included height, weight, body mass index (BMI), lean body mass and body fat mass (BFM). A height-meter (Seca Model $220 \mathrm{CE}$, Germany) calibrated from 0 to $200 \mathrm{~cm}$ was used to measure the height of each participant to the nearest $0.1 \mathrm{~cm}$. The participants' heels, back and occiput touched the stadiometer scale with the participants looking straight ahead during measurement. Body weight in light clothes was measured to the nearest $0.1 \mathrm{~kg}$ using a weighing scale (Seca Model 762 1019009 CE, Vogel \& Halke, Germany) calibrated from 0 to 120 $\mathrm{kg}$ with the participant in standing position with shoes off. A bioelectric impedance analysis (BIA) machine (Omron BF306; Model HBF-306-E CE, Japan) was used to measure the percentage body fat $(\mathrm{PBF})$ of all participants. BFM was calculated from the BIA estimate of PBF using the formula: $\mathrm{BFM}=(\mathrm{PBF} \times$ total body weight)/100. Lean body mass $(\mathrm{kg})$ was calculated from the PBF estimate from the BIA machine. Lean body mass $(\mathrm{kg})$ was calculated by subtracting BFM $(\mathrm{kg})$ from total body weight $(\mathrm{kg})$.

\section{Procedures}

The test procedure was explained and demonstrated to the participants at inclusion. Prior to the test, the participants warmed up using a Sportop bicycle ergometer (B600 model, UK) unloaded for $2 \mathrm{~min}$ at self-determined speed, $5 \mathrm{~min}$ before the test as recommended by Alaranta [6]. However, for consistency in the assessment of static back endurance, the principal author alone carried out the test for all the participants.

The participant lay on the examination table in the prone position with the upper edge of the iliac crests aligned with the edge of the table. The lower body was fixed to the table by two nonelastic straps, located around the pelvis and ankles, respectively, with a pillow used to relieve stress on the ankle joint. With the arms held along the sides touching the body, the participant was asked to isometrically maintain the upper body in a horizontal position. Horizontality was ensured by asking the participant to maintain contact between his/her back and a weighted ball hanging from a Guthrie Smith frame as shown in figure 1. Once a loss of contact with the weighted ball for more than $10 \mathrm{~s}$ was noticed the participant was encouraged once to immediately maintain contact again. If the position was not immediately corrected, or if the participant claimed he could no longer hold the position due to fatigue, discomfort or pain the test was ended. The total time from the onset of the test to trunk flexion and loss of the static neutral position was recorded as the endurance time or the isometric holding time (in seconds) using the stop watch (Quartz USA). The test was conducted only once and thereafter the participants were discharged as previously described $[3,10,18,19]$.

\section{Data Analyses}

Of the 376 healthy volunteers, data of 373 (190 males and 183 females) participants whose ages ranged between 21 and 60 years were analyzed. The data of the other 3 participants aged $60+$ years were not analyzed because 3 were adjudged to be insufficient for meaningful analysis. For the purpose of constructing gender and age reference value tables for static back extensor endurance, the participants were classified into four age groups on a 10 -year interval basis: $21-30,31-40,41-50,51-60$ years, respectively. Data were summarized using the descriptive statistics of mean, standard deviation and percentile. Poor endurance was defined as position-holding time that is less than the 25 th percentile, medium 
Fig. 1. Modified BSME.

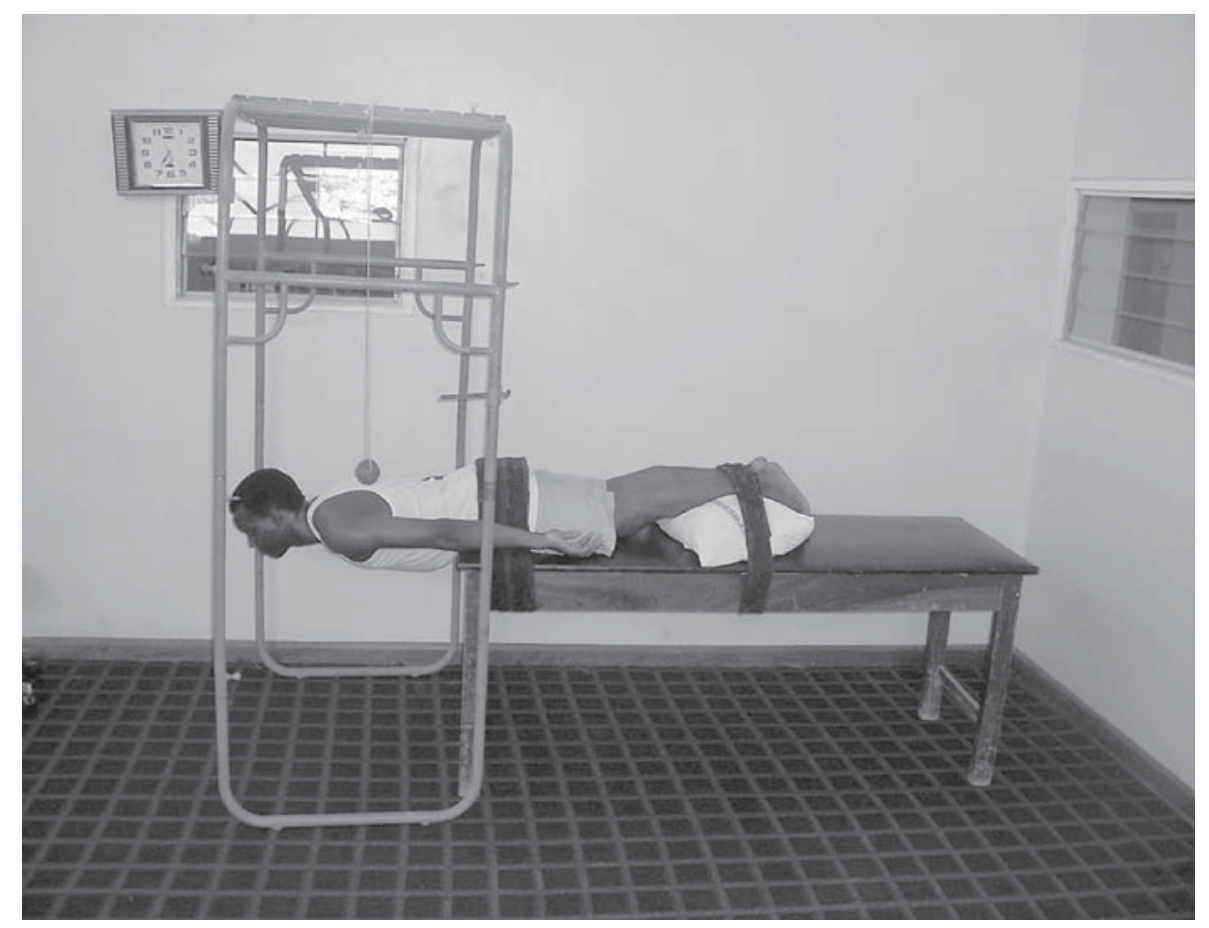

endurance as a position-holding time that ranged between the 25th percentile and 75th percentile and good endurance as position-holding time that is greater than 75 th percentile. Inferential statistics involving independent $t$ test and analysis of variance (ANOVA) were also used. The alpha level was set at 0.05 . The data analyses were carried out using SPSS 13.0 version software (SPSS Inc., Chicago, Ill., USA).

\section{Results}

The mean age, height, weight, and BMI of the participants were $38.7 \pm 13.4$ years, $1.65 \pm 0.08 \mathrm{~m}, 63.8 \pm 12.0$ $\mathrm{kg}$, and $23.6 \pm 4.35 \mathrm{~kg} / \mathrm{m}^{2}$, respectively. The one-way ANOVA and LSD post-hoc multiple comparison of ages, anthropometric parameters and endurance time of the participants across different age distribution are summarized in table 1. ANOVA showed that endurance time differed across the age groups $(\mathrm{p}=0.000)$. The post-hoc analysis showed that endurance time differed significantly between paired groups, except between age groups 31-40 and 41-50 years. Endurance time decreased with increasing age and ANOVA also revealed a significant difference between the anthropometric variables of the participants (table 1).

Static Back Endurance Values in Healthy Nigerian Adults
The mean values and percentile data for the static back endurance test of all of the participants by gender and age is presented in table 2 . Independent $t$ test analysis showed that males had a significantly $(\mathrm{t}=2.583 ; \mathrm{p}=0.010)$ higher mean endurance time than the females (119 \pm 49.8 vs. $106 \pm 47.6 \mathrm{~s})$. On age classification, there was no significant gender difference in endurance time in age groups $21-30$ years $(\mathrm{p}=0.072), 31-40$ years $(\mathrm{p}=0.903)$ and $51-60$ years $(\mathrm{p}=0.378)$, respectively. However, there was a significant gender difference $(\mathrm{p}=0.012)$ in endurance time in age group $41-50$ years. The highest mean endurance time (151 $\pm 44.9 \mathrm{~s})$ was in the youngest age group (21-30 years) for both males $(151 \pm 44.9 \mathrm{~s})$ and females (138 \pm $44.0 \mathrm{~s}$ ). The mean endurance time showed a more clearly definitive pattern as it decreased with increasing age except in males where it increased in the age group of $41-50$ years. There was a difference in the median values of males and females. The gender and age variations in the median values are also presented in table 2 .

Using the percentile cut-points, less than 72 and $64 \mathrm{~s}$ were regarded as poor endurance for males and females, respectively; 72-161 and 64-142 s as medium endurance for males and females, respectively, while 162-240 and 143-236s were regarded as good endurance for males and females, respectively. 
Table 1. Summary of one-way ANOVA and LSD post-hoc multiple comparison of the general characteristics and endurance time among the participants in the different age groups (mean $\pm S D, n=373$ )

\begin{tabular}{lllllrl}
\hline Variables & $\begin{array}{l}21-30 \text { years } \\
(\mathrm{n}=150)\end{array}$ & $\begin{array}{l}31-40 \text { years } \\
(\mathrm{n}=50)\end{array}$ & $\begin{array}{l}41-50 \text { years } \\
(\mathrm{n}=64)\end{array}$ & $\begin{array}{l}51-60 \text { years } \\
(\mathrm{n}=109)\end{array}$ & F ratio & p value \\
\hline Age & $24.3 \pm 2.90^{\mathrm{a}}$ & $36.8 \pm 3.43^{\mathrm{b}}$ & $46.1 \pm 3.01^{\mathrm{c}}$ & $55.0 \pm 2.78^{\mathrm{d}}$ & $2,420.4$ & 0.000 \\
Height & $1.66 \pm 0.09^{\mathrm{a}}$ & $1.63 \pm 0.07^{\mathrm{a}}$ & $1.65 \pm 0.08^{\mathrm{a}}$ & $1.64 \pm 0.07^{\mathrm{a}}$ & 1.571 & 0.196 \\
Weight & $61.4 \pm 10.5^{\mathrm{a}}$ & $63.0 \pm 10.1$ & $65.1 \pm 13.6^{\mathrm{b}}$ & $66.5 \pm 13.3^{\mathrm{c}}$ & 4.212 & 0.006 \\
BMI & $22.3 \pm 3.72^{\mathrm{a}}$ & $23.6 \pm 3.54$ & $24.5 \pm 5.09^{\mathrm{b}}$ & $24.7 \pm 4.61^{\mathrm{b}}$ & 7.033 & 0.000 \\
PBF & $21.6 \pm 8.32^{\mathrm{a}}$ & $26.0 \pm 8.31^{\mathrm{b}}$ & $30.9 \pm 9.42^{\mathrm{c}}$ & $30.9 \pm 8.10^{\mathrm{c}}$ & 32.007 & 0.000 \\
LBM & $47.7 \pm 7.75^{\mathrm{a}}$ & $46.3 \pm 7.42$ & $44.3 \pm 7.42^{\mathrm{b}}$ & $45.2 \pm 7.21^{\mathrm{b}}$ & 4.190 & 0.006 \\
BFM & $13.6 \pm 7.14^{\mathrm{a}}$ & $16.6 \pm 6.94^{\mathrm{b}}$ & $20.8 \pm 9.66^{\mathrm{c}}$ & $21.3 \pm 8.78^{\mathrm{c}}$ & 23.155 & 0.000 \\
ET & $145 \pm 44.7^{\mathrm{a}}$ & $109 \pm 36.3^{\mathrm{b}}$ & $103 \pm 46.2^{\mathrm{b}}$ & $77 \pm 30.3^{\mathrm{c}}$ & 62.287 & 0.000 \\
\hline
\end{tabular}

For a particular variable, mode means with different superscript are significantly $(\mathrm{p}<0.05)$ different. Mode means with same superscripts are not significantly $(\mathrm{p}>0.05)$ different. When only one contrast is significant, one of the cell means has no superscript attached. The pair of cell means that is significant has different superscripts. $\mathrm{BMI}=$ Body mass index; $\mathrm{PBF}=$ percentage body fat $\mathrm{LBM}=$ lean body mass; $\mathrm{BFM}=$ body fat mass (fat weight); ET = endurance time; $\mathrm{SD}=$ standard deviation.

Table 2. Baseline mean and percentile data for static back endurance test of all the subjects by age and gender $(\mathrm{n}=373)$

\begin{tabular}{|c|c|c|c|c|c|c|c|c|}
\hline \multicolumn{3}{|l|}{ Subjects } & \multicolumn{6}{|c|}{ Endurance time, s } \\
\hline age group & gender & $\mathrm{n}$ & mean $\pm S D$ & minimum & 25th percentile & median & 75th percentile & maximum \\
\hline \multirow[t]{3}{*}{$21-60$ years } & $\mathrm{M}$ & 190 & $119 \pm 49.8$ & 28.0 & 72.0 & 112.0 & 162.3 & 240.0 \\
\hline & $\mathrm{F}$ & 183 & $106 \pm 47.6$ & 22.0 & 64.0 & 98.0 & 142.0 & 236.0 \\
\hline & $(\mathrm{M}+\mathrm{F})$ & 373 & $113 \pm 49.1$ & 22.0 & 69.0 & 104.0 & 156.0 & 240.0 \\
\hline \multirow[t]{3}{*}{$21-30$ years } & $\mathrm{M}$ & 82 & $151 \pm 44.9$ & 50.0 & 119 & 160 & 185 & 240.0 \\
\hline & $\mathrm{F}$ & 68 & $138 \pm 44.0$ & 56.0 & 108.3 & 142.5 & 169.5 & 236.0 \\
\hline & $(\mathrm{M}+\mathrm{F})$ & 150 & $145 \pm 44.7$ & 50.0 & 110.0 & 152.0 & 178.0 & 240.0 \\
\hline \multirow[t]{3}{*}{$31-40$ years } & $\mathrm{M}$ & 23 & $108 \pm 32.7$ & 56.0 & 88.0 & 104.0 & 125.0 & 176.0 \\
\hline & $\mathrm{F}$ & 27 & $109 \pm 36.7$ & 56.0 & 74.0 & 98.0 & 136.0 & 188.0 \\
\hline & $(\mathrm{M}+\mathrm{F})$ & 50 & $109 \pm 36.3$ & 56.0 & 79.8 & 104.0 & 132.0 & 188.0 \\
\hline \multirow[t]{3}{*}{$41-50$ years } & M & 27 & $119 \pm 44.2$ & 48.0 & 82.0 & 128.0 & 156.0 & 192.0 \\
\hline & $\mathrm{F}$ & 37 & $90 \pm 44.3$ & 36.0 & 58.0 & 76.0 & 108.5 & 232.0 \\
\hline & $(\mathrm{M}+\mathrm{F})$ & 64 & $103 \pm 46.2$ & 36.0 & 59.8 & 93.5 & 138.0 & 232.0 \\
\hline \multirow[t]{3}{*}{$51-60$ years } & M & 58 & $79 \pm 31.3$ & 28.0 & 58.0 & 72.0 & 96.5 & 205.0 \\
\hline & $\mathrm{F}$ & 51 & $74 \pm 29.1$ & 22.0 & 57.0 & 64.0 & 98.0 & 136.0 \\
\hline & $(\mathrm{M}+\mathrm{F})$ & 109 & $77 \pm 30.3$ & 22.0 & 57.5 & 70.0 & 97.0 & 205.0 \\
\hline
\end{tabular}

$\mathrm{BMI}=$ Body mass index; $\mathrm{M}=$ male; $\mathrm{F}=$ female.

\section{Discussion}

Endurance capabilities of the back extensor muscles are reported to be important or even more important than strength in the prevention and treatment of LBP [6].
Identifying high or low muscular endurance can alert the patient and clinician to a need for possible modifications to the usual treatment regime [16]. It is recommended that clinicians who treat LBP can use established baseline data on low back endurance among normal subjects as a 
means to recognize decreased back muscle endurance as one of the impairments resulting from LBP or as an outcome measure to help evaluate residual disability. This is the first study to provide reference values of static endurance of the back extensor muscles in healthy Nigerians.

Mean values for static back endurance have been documented from previous studies among normal adults for different populations [3, 10, 16, 19, 20]. Moreau et al. [19] in a review summarized that the mean extensor endurance time for mixed-sex groups ranges from 77.76 to $129 \mathrm{~s}$ in healthy subjects using the original Sørensen test or its variants. Mean static endurance (113 s) among Nigerians of both genders is within the previously reported range but lower than normal Biering-Sørensen endurance times (198 s) [3]. However, only few studies from countries such as the USA [2, 20], Finland [10], and Canada [17] have reported normative values in the general population.

From this study, healthy adult Nigerian males have significantly greater back extensor muscle endurance than their female counterparts (119 vs. 106 s), a finding not consistent with numerous reports suggesting that females have a greater muscular endurance capacity when compared to males [3, 18, 21, 22]. However, our finding is consistent with two other reports $[2,10]$. The disparity in patterns of static back endurance resulting in a wide range of mean endurance times from previous studies may be a result of numerous methodological variations and sample differences which may translate into considerable discrepancies in the findings. For example, Alaranta et al. [10] established normative data for static back endurance but did not discriminate between subjects with and without LBP in the study sample; McIntosh et al. [16] established normative data for isometric back endurance using a static chest raise test while Lanning et al. [20] sampled healthy college-aged athletes. This present study involved homogeneously indigent Africans without reported LBP. We imply that ethnic and racial differences may have a strong influence on the pattern of low back endurance. However, this is open to speculations and further research is warranted. However, our results show no significant gender differences in the endurance times of participants within the same age strata except in the 41-50 year age category with women having lower static back endurance than men. This age bracket represents the postreproductive and menopausal period for most women [23] with consequent decline in muscular performance $[24,25]$. The accumulative effects of the many musculoskeletal changes associated with pregnancy, parturition and parity which include postural chang- es, joint laxity, reduction in muscle strength and LBP [26-28] may account for poor endurance of the trunk muscles among women in this age group. Mbada et al. [29] in a previous study reported that decreased static back endurance is a residual impairment precipitated by pregnancy and parturition among parous women. They noted, however, that the decreased back muscle endurance secondary to pregnancy is clearly related to parity and it seems not to resolve like the other musculoskeletal changes in pregnancy.

We found static back endurance to decline with advancing age among both genders. This is consistent with previous reports that muscle endurance decreases with increasing age because of poor muscle function as a result of decreased muscle mass, age-related decline in strength which appears to be greater in back and lower extremity muscles, and decreasing aerobic capacity average of approximately $1 \%$ per year after the third decade $[3,8,10$, $12,30]$. Conversely, static back endurance in the age group 41-50 years, although lower than that of the age group 31-40 years, was not significant. Our results suggest that the significant anthropometric differences in the different age strata could contribute to the difference in endurance between them. Several anthropometric measures have been considered in relation to back endurance such as BMI, body weight, height, body fat and lean body mass [31]. Specifically, an increase in body fat level has been implicated in the etiology of decreased endurance of the back muscles [32, 33], but the potential influence of stature remains debatable $[10,30,34]$.

A potential limitation of this study was the nonrandomization of the study population, as the participants were volunteers who were recruited consecutively. We tried to minimize the effect of motivation by giving the participants full information about the nature of the test and they were all given uniform and standardized encouragement during testing.

\section{Conclusion}

This study established a reference set of values according to age and gender for static back endurance using modified Sørensen's test for healthy Nigerians. In general, males had significantly greater back extensor muscle endurance than females. 


\section{References}

1 Burnett CN, Glenn TM: Principles of aerobic exercise; in Kisner C, Colby LA (eds): Therapeutic Exercise: Foundations and Techniques, ed 3. New Delhi, Jaypee Brothers, 1996, pp 111-142.

2 Mayer T, Gatchel R, Betancur J, Bovasso E: Trunk muscle endurance measurement: isometric contrasted to isotonic testing in normal subjects. Spine 1995;20:920-926.

-3 Biering-Sørensen F: Physical measurements as risk indicators for low-back trouble over a one-year period. Spine 1984;9:106-119.

4 Nicolaisen T, Jörgensen K: Trunk strength, back muscle endurance and low-back trouble. Scand J Rehabil Med 1985;17:121-127.

5 Moffroid MT, Haugh LD, Haig AJ, Henry SM, Pope MH: Endurance training of trunk extensor muscles. Phys Ther 1993;73:10-17.

6 Alaranta H: Strength and endurance testing; in Yeomans SG: The Clinical Application of Outcomes Assessment. Stamford, Appleton \& Lang, 2000, pp 158-162.

7 Udermann BE, Mayer JM, Graves JE, Murray SR: Quantitative assessment of lumbar paraspinal muscle endurance. J Athl Train 2003;38:259-262.

8 Ropponen A: The role of heredity, other constitutional structural and behavioral factors in back function tests. Studies in Sport, Physical Education and Health, University of Jyväskylä, Jyväskylä, 2006, p 78.

-9 Mannion AF, Taimela S, Müntener M, Dvorak J: Active therapy for chronic low back pain. Part 1. Effects on back muscle activation, fatigability, and strength. Spine 2001; 26:897-908.

10 Alaranta H, Hurri H, Heliovaara M, Soukka A, Harju R: Non-dynamometric trunk performance tests: reliability and normative data. Scand J Rehabil Med 1994;26:211-215.

-11 Sparto PJ, Parnianpour M, Barria EA, Jagadeesh JM: Wavelet analysis of electromyography for back muscle fatigue detection during isokinetic constant-torque exertions. Spine 1999;24:1791-1798.

-12 Gomer FE, Silverstein LD, Berg WK, Lassiter DL: Changes in electromyographic activity associated with occupational stress and poor performance in the work place. Hum Factors 1987;29:131-143.
13 Lee JH, Hoshino Y, Nakamura K, Kariya Y, Saita K, Ito K: Trunk muscle weakness as a risk factor for low back pain: a 5-year prospective study. Spine 1999;24:54-57.

14 Roy SH, Deluca CJ, Casavant DA: Lumbar muscle fatigue and chronic low back pain. Spine 1989;14:992-1001.

15 Wilder DG, Aleksiev AR: Muscle response to sudden load: a tool to evaluate fatigue and rehabilitation. Spine 1996;21:2628-2639.

16 McIntosh G, Wilson L, Affieck M, Hall H: Trunk and lower extremity muscle endurance: normative data for adults. J Rehabil Outcome Meas 1998;2:20-39.

17 McGill SM, Childs A, Liebenson C: Endurance times for back stabilization exercises: clinical targets for testing and training from a normal database. Arch Phys Med Rehabil 1999;80:941-944.

18 Luoto S, Heliovaara M, Hurri H, Alaranta H: Static back endurance and the risk of lowback pain. Clin Biomech 1995;10:323-324.

19 Moreau CE, Green BN, Johnson CD, Moreau SR: Isometric back endurance tests: a review of the literature. J Manipulative Physiol Ther 2001;24:110-120.

20 Lanning CL, Uhl TL, Ingram CL, Mattacola CG, English T, Newsom S: Baseline values of trunk endurance and hip strength in collegiate athletes. J Athl Train 2006;41:427434.

21 Umezu Y, Kawazu T, Tajima F, Ogata H: Spectral electromyographic fatigue analysis of back muscles in healthy adult women compared with men. Arch Phys Med Rehabil 1998;79:536-538.

22 Allman BL, Rice CL: Neuromuscular fatigue and aging: central and peripheral factors. Muscle Nerve 2002;25:785-796.

23 Kumar JP, Clark LM: Disease: the menopause; in Clinical Medicine, 6 ed. London, Saunders, 2007, chap 18, p 1052.

24 Aloia JF, McGowan DM, Vaswani AN, Ross P, Cohn CH: Relationship of menopause to skeletal and muscle mass. Am J Clin Nutr 1991;53:1378-1383.
25 Greeves JP, Cable NT, Reilly T, Kingsland C: Changes in muscle strength in women following the menopause: a longitudinal assessment of the efficacy of hormone replacement therapy. Clin Sci (Lond) 1999;97: 79-84.

-26 Damen L, Buyruk HM, Guler-Uysal F, Lotgering FK, Snijders CJ, Stam HJ: The prognostic value of asymmetric laxity of the sacroiliac joints in pregnancy related pelvic pain. Spine 2002;27:2820-2824.

27 Ostgaard HC, Andersson GB, Karlsson K: Prevalence of back pain in pregnancy. Spine 1991;16:549-552.

28 Perkins J, Hammer RL, Loubert PV: Identification and management of pregnancy-related low back pain. J Nurse Midwifery 1998; 43:331-340.

-29 Mbada CE, Ojedoyin OO, Ayanniyi O, Adeyemi $\mathrm{AB}$, Olagbegi OM, Adekanla BA, Eesuola OO: Comparative assessment of back extensor muscles' endurance between nulliparous and parous women. J Back Musculoskel Rehabil 2007;20:143-147.

30 Latikka P, Battié MC, Videman T, Gibbons LE: Correlations of isokinetic and psychophysical back lift and static back extensor endurance tests in men. Clin Biomech 1995;10: 325-330

31 Mannion AF, Müntener M, Taimela S, Dvorak J: A randomized clinical trial of three active therapies for chronic low back pain. Spine 1999;24:2435-2448.

32 Gibbons LE, Videman T, Battié MC: Determinants of isokinetic and psychophysical lifting strength and static back muscle endurance: a study of male monozygotic twins. Spine 1997;22:2983-2990.

- 33 Kankaanpää M, Laaksonen D, Taimela S, Kokko SM, Airaksinen O, Hanninen O: Age, sex, and body mass index as determinants of back and hip extensor fatigue in the isometric Sørensen back endurance test. Arch Phys Med Rehabil 1998;79:1069-1075.

34 Demoulin C, Vanderthommen M, Duysens C, Crielaard J: Spinal muscle evaluation using the Sørensen test: a critical appraisal of the literature. Joint Bone Spine 2006;B73: 43-50. 